\title{
Applicability of the Polyphenylene Oxide Film Dosimeter to High UV Exposures in Aquatic Environments
}

\author{
P W Schouten ${ }^{\mathrm{a}^{*}}$, A V Parisi ${ }^{\mathrm{a}, \mathrm{b}}$ \& D J Turnbull ${ }^{\mathrm{a}, \mathrm{b}}$ \\ ${ }^{a}$ Department of Biological and Physical Sciences, Faculty of Sciences, University of \\ Southern Queensland, Toowoomba, Australia 4350. \\ b Centre for Rural and Remote Area Health, Faculty of Sciences, University of \\ Southern Queensland, Toowoomba, Australia 4350.
}

Keywords: Solar UV, Ultraviolet, Underwater, Aquatic, Marine, Field, Dosimeter, Badge, Film

*To whom correspondence should be addressed at: schouten@usq.edu.au 


\section{ABSTRACT}

Previous research has proven that the Poly (2,6-dimethyl-1, 4-phenylene oxide) (PPO) dosimeter is capable of receiving both in-air and underwater UV exposures that are significantly greater than those of the more commonly used polysulphone dosimeter, within a range of accuracy close to what would be expected of dosimetric measurements made in-air provided that the necessary calibrations are completed correctly by factoring in different atmospheric column ozone levels, SZA ranges, varying water turbidity and DOM levels. However, there is yet to be an investigation detailing the performance of the PPO dosimeter and its ability to measure UV in an actual field environment over an extended period of time. This research aims to bridge this gap in the knowledge by presenting a measurement campaign carried out in two real world aquatic environments and a simulated sea water environment using a batch of PPO dosimeters set at different depths and aligned to a range of different angles and geographical directions by means of attachment to a custom built dosimeter submersible float (DSF) unit over the space of a year at a sub-tropical location. Results obtained from this measurement campaign were used to compute a $\mathrm{K}_{\mathrm{d}}$ value for the sea water in each particular season. These $K_{d}$ values where found to be in close agreement to standalone $\mathrm{K}_{\mathrm{d}}$ values derived from results taken using a standard calibrated spectrometer in the same sea water. 


\section{INTRODUCTION}

The current global warming trend in unison with recent fluctuations in atmospheric column ozone levels have resulted in changes occurring to the penetrative ability and distribution of the solar ultraviolet (UV) (280 to $400 \mathrm{~nm}$ ) light field as measured in underwater locations such as in lakes, creeks, dams and the ocean. The solar UV, in particular the ultraviolet-B (UVB) (280 to $320 \mathrm{~nm}$ ), has been shown by a vast number of studies to have a significantly detrimental effect on many different types of underwater life, ranging from the big to the small, each having their own special niche within the delicate marine ecosystem, which has direct consequences to our own life here on Earth $[1,2,3,4,5]$. Therefore, it is of utmost importance that the attributes of the underwater UV are measured and documented in order to enhance our understanding of its widespread influence upon the aquatic world.

The influence of solar UV radiation upon aquatic ecosystems is presently a highly investigated topic [6]. It is a well known fact that solar UV, in both its ultraviolet-A (UVA) (320 to $400 \mathrm{~nm}$ ) and UVB components, does have a detrimental impact upon marine organisms. Following varying levels of solar UV exposure, reduced rates in reproduction, growth and development and a higher amount of mutations have been seen to occur in species such as phytoplankton, zooplankton, fish eggs and larvae, and also macroalgae [7].

Increases in the amount of incoming solar UV into a marine ecosystem, such as those caused by decreases on atmospheric ozone levels for instance, can lead to decreases in biomass productivity, which affect each level of the food chain, working all the way to the top with reduced food production available for human consumption [8]. In 
addition to this, there would be a noticeable reduction in the global sink capacity for carbon dioxide alongside wide scale changes in marine species composition [8, 9].

So there is a definite need for the continual measurement and monitoring of solar UV in a wide variety of underwater environments in order to further quantify and predict the damaging influence solar UV has upon the fragile aquatic life cycle. For underwater UV measurements, UV dosimeters have often been overlooked as a measurement tool by researchers, with most investigations employing spectroradiometers, spectrometers or radiometers to do the bulk of the work. These instruments have been highly useful for taking underwater measurements of the UV sporadically over a short time frame. However, over long periods of time these spectroradiometers and radiometers become harder to employ, with sizeable amounts of time and effort needed to accurately calibrate and maintain them.

There are several recent examples of underwater UV measurement work using spectroradiometers, spectrometers or radiometers in numerous types of water bodies located across the world. Hanelt et al. [10] used a spectroradiometer system with a custom diffuser housing to measure UVB radiation distributions in an arctic fjord. Dring et al. [11] used an underwater light sensor to make daily UV measurements in the Helgoland region of the North Sea over a time period of six years. Frenette et al. [12] measured the depth profiles of both UV and photosynthetically active radiation (PAR) in Lake Saint Pierre, Quebec with a spectroradiometer. Reinhart et al. [13] also employed a spectroradiometer to measure both spectral UV and PAR at set depth increments in order to estimate various optical properties of Lake Verevi, Estonia. Also, again with the use of a spectroradiometer, Schubert et al. [14] investigated 
variations in UV and PAR spectral irradiance levels in a shallow estuary on the southern coastline of the Baltic Sea. In comparison to this there have been only a few underwater investigations made with UV dosimeters.

Polysulphone has been deployed previously in underwater locales in the field in two different studies. The first was carried out by Dunne [15], where UVB radiation was measured using polysulphone dosimeters in seawater at tropical latitudes. The author discovered that the polysulphone dosimeters could obtain a UVB response within a 5\% error threshold over a depth range of between 2.2 and $7.0 \mathrm{~m}$, depending upon the turbidity of the seawater. Only small exposures of between 1.5 to $40.0 \mathrm{~kJ} \mathrm{~m}^{-2}$ could be measured during deployment time. The second most recent study was completed by Frost et al. [16] who successfully used polysulphone to estimate attenuation coefficients in shaded water bodies in the North-east region of the United States.

Although these studies were successful in measuring underwater solar UVB, polysulphone is still restricted by the fact that it only has a limited dynamic range in comparison to Poly (2,6-dimethyl-1, 4-phenylene oxide) (PPO) film. This difference in dynamic range has been shown to be many times greater than polysulphone at subtropical latitudes [17]. This allows the PPO dosimeter to stay in use in the field for a much longer period of time when compared to polysulphone. Even though it has a much greater dynamic range, the PPO dosimeter has similar optical and physical characteristics to the polysulphone dosimeter. It has no temperature dependence, a relatively minimal dark reaction effect, a good cosine response, in-air variation of less than $\pm 10 \%$ and like the polysulphone dosimeter it possesses a response spectrum that closely resembles the erythemal action spectrum [17]. Previous investigations have 
shown that the PPO film dosimeter can be used to measure in-air personal UV exposures on humans over extended time intervals [18, 19, 20]. Following up on this work, PPO film dosimeters have been tested for use underwater in two recent studies carried out in controlled environments [21, 22].

Results have been presented describing general optical properties of the PPO dosimeter when submerged in clean tap water in an indoors laboratory environment [21]. The properties that were analysed in this study included UVB dose-response depth profiling, cosine response, interdosimeter variation, dose rate independence, UVA and visible wavelength responsivity, water marking effect with temperature dependence and exposure additivity. From this work it was found that PPO could be used as a viable underwater dosimeter as long as strict calibration and error correction procedures were implemented.

Following this, the calibration methodology necessary to produce accurate UVB measurements with the PPO dosimeter outdoors in the field was investigated in four different varieties of water each having their own characteristic spectral transmission and absorption characteristics [22]. This research discovered that calibrations for the PPO dosimeter can be transferred from one water type to another at any depth, as long as the water types under analysis had similar overall spectral transmission and absorption properties. It was also found that calibrations measured for the PPO dosimeter in air could not be employed for use in the underwater environment. In addition, it was shown that the PPO film could be exposed to seven to eight times as much solar UV in comparison to polysulphone before the beginning of optical saturation when underwater. This investigation along with the outcomes provided by 
Casale et al. [23] also showed that UV measurements obtained from chemical film dosimeters are susceptible to fluctuations in atmospheric ozone and also to seasonal changes in the solar zenith angle (SZA) and that this must be taken into account before beginning a series of measurements in the field.

Unlike polysulphone, the PPO dosimeter has yet to be tested in real world underwater environments. Therefore, the objective of this investigation was to deploy PPO dosimeters using a novel dosimeter submersible float (DSF) apparatus in three distinct underwater locales, each with their own particular characteristic constituents. These locales being a moderately turbid creek located within the confines of a public garden, an abandoned agricultural engineering dam site holding extremely turbid stagnant water and a large rust proofed water tank filled with clean sea water sourced from a coastal location. From this the applicability of PPO dosimeters to measure high UVB exposures at a range of different depths, alignments and geographical directions in these aquatic environments was evaluated. This was undertaken in each season throughout a single year and the data obtained was employed to calculate attenuation coefficients $\left(K_{d}\right)$ for each water type. As a final test, these dosimetric $K_{d}$ values were directly compared to $\mathrm{K}_{\mathrm{d}}$ values calculated using a standard calibrated spectrometer.

\section{MATERIALS AND METHODS}

\section{PPO Dosimeter Calibration and Immersion Effect Corrections}

The fabrication, preparation and measurement technique for the PPO dosimeter has been previously described in Lester et al. and Schouten et al. [20, 21, 22]. To ensure maximum accuracy, the PPO dosimeters used in this research were calibrated over the waveband running from $298 \mathrm{~nm}$ to $320 \mathrm{~nm}$ for both in-air and underwater use against 
an immersion effect corrected EPP2000 spectrometer (StellarNet EPP2000 C-UVVIS, Tampa, Florida). Calibrations were performed over each season at the University of Southern Queensland Toowoomba campus, Australia (27 33’ S, $151^{\circ} 57^{\prime}$ E, $691 \mathrm{~m}$ elevation) for each water type under analysis in this research from early 2007 through to early 2008 in order to factor in every possible SZA and a range of varying atmospheric parameters. The lower limit of $298 \mathrm{~nm}$ was chosen as it was the cut-off wavelength at which the EPP2000 spectrometer could obtain reliable underwater data. The upper limit of $320 \mathrm{~nm}$ was chosen as it has been used by photobiologists to denote the end of the UVB waveband and is more applicable to this research. The immersion effect is known to occur whenever any optical meter is submerged underwater to take a light measurement. A larger amount of electromagnetic radiation is backscattered out of the meter during a water-based measurement in comparison to an air-based measurement. This is due to the discrepancies between the refractive indices for air and water at the collector interface. The methodology employed to calculate immersion factors for optical instrumentation has been detailed in previous studies $[24,25,26]$ with the actual immersion factors for the EPP2000 spectrometer provided in [22].

\section{Dosimeter Submersible Float Specifications}

The DSF employed for the field measurement campaign was fabricated by combining an aluminium frame and a PVC ballast cylinder with a total height of $64 \mathrm{~cm}$, a width of $26 \mathrm{~cm}$ and a cross-sectional length of $67 \mathrm{~cm}$. The PVC ballast cylinder had a volume of approximately 13 litres. This cylinder was filled with either small stones or gravel in order to ensure that the float would remain in its required upright stationary position throughout the duration of the given series of measurements. Four steel hook 
anchors were also inserted through holes in the floor of the DSF and straight into the ground in order to increase its stability in the water during windy conditions.

The DSF had a column of four dosimeter attachment sites resting on each of its four sides. Each side of the DSF was positioned around the PVC ballast cylinder in $90^{\circ}$ increments so that measurements for each geographical direction (north, south, east and west) could be made. In each of the four sides each attachment site was separated by a distance of $15 \mathrm{~cm}$. The top attachment site was designed to remain above the water level at all times throughout each measurement series, while the three lower attachment sites were to receive UVB exposures underwater. These three underwater attachment sites received UVB exposures at depths of $5 \mathrm{~cm}\left(\mathrm{Z}_{5 \mathrm{CM}}\right), 20 \mathrm{~cm}\left(\mathrm{Z}_{20 \mathrm{CM}}\right)$ and $35 \mathrm{~cm}\left(\mathrm{Z}_{35 \mathrm{CM}}\right)$ respectively.

All the attachment sites were able to hold up to three dosimeters at a time without obstruction, with each dosimeter set to different angular inclinations which were $0^{\circ}$ to the horizontal (horizontally aligned), $45^{\circ}$ to the horizontal (diagonally aligned) and $90^{\circ}$ to the horizontal (vertically aligned). In all of the different water types, each of the dosimeters were checked regularly for any mud, moss or organic matter residue build up on their surfaces. Figure 1 (A) displays the north side of the DSF with a full payload of PPO dosimeters ready for deployment. Figure 1 (B) shows the top-down view of the DSF. Due to the geometry of the DSF, some minor shading of the $\mathrm{Z}_{20 \mathrm{CM}}$ and the $\mathrm{Z}_{35 \mathrm{CM}}$ dosimeters was found to occur during the measurements carried out in each underwater environment, influencing the amount of diffuse irradiance scattered upon the dosimeters. This shading took place most generally during high SZA conditions, such as in the early morning and in the late afternoon, where solar UV was 
incident predominantly on the sides of the DSF in comparison to low SZA conditions in which solar UV was incident towards the top of the DSF.

To calculate $\mathrm{K}_{\mathrm{d}}$ values only UVB exposure data measured at the $0^{\circ}$ angular inclination was used. The calibrated UVB exposure data gathered at each of the three depths was used in conjunction with the modified Beer Lambert Bouguer Law which is of the form:

$$
\ln \left(\frac{U V B^{z}{ }_{\text {EXPOSURE }}}{U V B^{z=0}{ }_{\text {EXPOSURE }}}\right)=-K_{d} z
$$

where $U V B^{z}{ }_{\text {EXPOSURE }}$ is the calibrated UVB exposure as measured by the PPO dosimeter at depth $\mathrm{z}$ in units of $\mathrm{kJ} \mathrm{m}^{-2}$ and $U V B^{\mathrm{z}=0}{ }_{\text {EXPOSURE }}$ is the calibrated UVB exposure as measured by the PPO dosimeters at the first attachment site just below the water surface in units of $\mathrm{kJ} \mathrm{m}^{-2}$. Linear regression analysis was performed with the modified Beer Lambert Bouguer Law in order to extract the value for $K_{d}$. A final $K_{d}$ estimate was determined by averaging together the particular $K_{d}$ values calculated for each geographical direction.

\section{Attenuation Coefficient Calculation for the Calibrated EPP2000}

\section{Spectrometer}

Evaluation of $K_{d}$ values for each of the three different water types were made using underwater UVB spectral irradiance data collected with the EPP2000 spectrometer during a measurement campaign over two cloud free days in early autumn (low SZA conditions ranging from $20^{\circ}$ to $61^{\circ}$ ) and two additional cloud free days in mid winter (high SZA conditions ranging from $39^{\circ}$ to $75^{\circ}$ ). Over the range of SZA encountered throughout the measurements made each day, for each water type at each depth, a 
UVB irradiance value was calculated by integrating the spectral UVB irradiance across the UVB waveband specified previously. This integrated UVB value was then included in a series of depth profiles. The modified Beer-Lambert-Bouguer Law was again used together with the depth profiles to find the necessary $\mathrm{K}_{\mathrm{d}}$ values in a similar way to how it was used with the dosimetric measurements, except irradiance data was used in the linear regression process instead of exposure data.

\section{Underwater UV Exposures at Different Aquatic Locales Japanese Gardens Creek}

A creek situated in a Japanese Garden located on the boundary of the University of Southern Queensland Toowoomba campus was used as the first field site in which to test the PPO dosimeter with the DSF. The creek had a measured length of 95 metres, width of 65 metres and an approximated depth of 4 metres. Measurements were carried out using the DSF in the creek in each season from early July 2007 to early April 2008. The number of days that the DSF was deployed in the environment was determined by the visible deterioration state of the dosimeters located at the top attachment site. If it could be seen that these dosimeters were becoming optically saturated (distinguished by a change in appearance of the film from clear to orange) the measurement series was brought to an end. This protocol was employed not only for the creek water measurements, but also for the agricultural dam water measurements and the sea water measurements. The length of time it took for the top attachment site dosimeters to degrade changed slightly for each particular season across the year-long measurement series. Winter measurements ran over the space of 12 days inclusive from 16 July to 27 July 2007. Spring measurements ran over the space of 9 days inclusive from 1 October to 9 October 2007. Summer measurements 
ran over the space of 10 days inclusive from 18 February to 28 February 2008. Autumn measurements ran over the space of 10 days inclusive from 31 March to 9 April 2008. During the deployments, the DSF was placed in a position located far enough away from the shoreline of the creek so that shading from nearby plants and trees was minimal.

\section{Simulated Sea Water Environment}

As the nearest coastline to Toowoomba is over $120 \mathrm{~km}$ away, it was decided that the $2^{\text {nd }}$ site for the PPO dosimeter field trials would be carried out in a large field simulated sea water environment instead of in the ocean itself. This negated the complexities that come into play during oceanic measurement campaigns such as high winds, turbulence, tidal changes and possible vandalism. The simulated sea water environment consisted of a circular steel water tank which had a circumference of 10 metres and a depth of $1 \frac{1 / 4}{4}$ metres. The sea water used in the tank was sourced from a

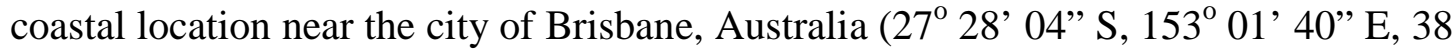
m elevation). The DSF was positioned exactly in the centre of the tank so that it would receive only a minimal amount of shading during the early morning and the late afternoon. In order to eliminate any leakage from the tank and the seepage of rust into the sea water, the tank was covered with three layers of extra strength pond liner. Measurements were carried out using the DSF in the sea water tank in each season from June 2007 to December 2008. Spring measurements ran over the space of 9 days inclusive from 14 November to 22 November 2007. Autumn measurements ran over the space of 10 days inclusive from 31 March to 9 April 2008. Winter measurements ran over the space of 12 days inclusive from 30 June to 11 July 2008. Summer 
measurements were carried out over a period of 6 days inclusive from 1 December to 6 December 2008.

\section{University of Southern Queensland Research Dam}

The $3^{\text {rd }}$ site selected for the PPO dosimeter field trials was an abandoned agricultural engineering research dam again located on site at the University of Southern Queensland, Toowoomba campus. The agricultural dam had a measured length of 21 metres, width of 19 metres and an estimated depth of 3 metres. UVB exposure measurements were carried out using the DSF in the agricultural dam in four seasons from July 2007 to December 2008. Winter measurements ran over the space of 12 days inclusive from 2 July to 13 July 2007. Spring measurements ran over the space of 9 days inclusive from 15 October to 23 October 2007. Autumn measurements ran over the space of 8 days from 16 April to 23 April 2008. The autumn measurement series was initially planned to run for 10 days in total but flooding of the dam after overnight torrential rain brought the trial to a halt. Summer measurements ran for 6 days inclusive from 1 December 2008 to 6 December 2008. A comparison between the transmission and absorption spectra at an arbitrary wavelength of $315 \mathrm{~nm}$ for each of the water types found in the agricultural dam, the sea water tank and the Japanese Gardens creek is displayed in Figure 2.

\section{RESULTS}

\section{Creek Water}

Measurement data collected with the DSF in the creek in autumn, winter, spring and summer can be seen in Figure 3 (A), (B), (C) and (D) respectively. The first 12 data blocks on the x-axis represent the daily averaged UVB exposures measured at the 
water surface running in order from the north, east, south and west cycling over the $0^{\circ}, 90^{\circ}, 45^{\circ}$ orientations for each particular direction. This order continues for each following set of 12 data blocks along the x-axis for all the depths from $5 \mathrm{~cm}$ to $20 \mathrm{~cm}$ to $35 \mathrm{~cm}$. The UVB exposure error was approximated as an accumulative $\pm 18 \%$ uncertainty that results from errors generated during measurement and analysis procedures. This $\pm 18 \%$ error threshold and the data presentation scheme remained the same for both the dam water and sea water measurements. At the water surface for each season it can be clearly seen from the figures that relatively high levels of UVB exposure were received by the dosimeters, which was to be expected as they were not submerged. Throughout each season at the water surface the largest exposures were generally recorded at either the north or west alignments usually at an inclination of $45^{\circ}$. The horizontally aligned dosimeters commonly intercepted UVB dosages comparable if not slightly less than those received at the $45^{\circ}$ inclination, with the vertically aligned dosimeters measuring the lowest amounts of solar UVB.

In the creek, measurements were able to be obtained at a depth of $5 \mathrm{~cm}$ across each particular measurement position. The general distribution of the exposures at this depth was extremely similar to what was seen with the exposures measured at the surface of the water. The highest exposures were again usually seen at either the north or west alignments at the $45^{\circ}$ inclination, except for the data collected in spring where the dosimeter aligned to the horizontal directed to the west received the most UVB. However, in each season the magnitude of the UVB exposures at the $5 \mathrm{~cm}$ depth was considerably reduced in comparison to the measurements made at the surface across every single position. For example, in autumn the maximum daily averaged exposure received at the surface was $57 \mathrm{~kJ} \mathrm{~m}^{-2}$ day ${ }^{-1}$ recorded at the north $45^{\circ}$ position. In 
comparison, at the same position $5 \mathrm{~cm}$ underwater the measurement recorded was 7.8 $\mathrm{kJ} \mathrm{m}^{-2}$ day $^{-1}$, a sizeable $86 \%$ reduction with respect to the surface UVB exposure. Again, in spring the maximum exposure was received at the north $45^{\circ}$ position with a value of $55 \mathrm{~kJ} \mathrm{~m}^{-2} \mathrm{day}^{-1}$. The measurement made at the same position $5 \mathrm{~cm}$ underwater was far less at $8 \mathrm{~kJ} \mathrm{~m}^{-2} \mathrm{day}^{-1}$, which represented another reduction in UVB exposure of approximately $86 \%$. As the DSF was anchored at a location in the creek so that it was not influenced by any shade produced by shoreline plants and trees, the most plausible explanation for the drastic reduction in UVB exposure would be due to the large clusters of organic matter produced by local wildlife such as ducks and birds and decaying plant matter that was observed to be floating through the water at regular intervals. This organic matter could have blocked the incoming UVB effectively shading the dosimeters positioned below it. Throughout the measurement campaign very few reliable UVB exposures were measured during any season at the $20 \mathrm{~cm}$ and the $35 \mathrm{~cm}$ depths in the creek. Even in summer where solar output it at its highest levels, it appears that the UVB wavelengths failed to penetrate the creek water any further than $5 \mathrm{~cm}$. This result meant that no depth profiles could be obtained for the creek water.

\section{Sea Water}

UVB exposure data measured using the DSF in the simulated sea water environment averaged over each day in autumn, winter, spring and summer can be seen in Figure 3 (A), (B), (C) and (D) respectively. As was shown in the creek water, it is seen from the figures that across every position UVB exposures received by the dosimeters at the water surface were far greater than those intercepted underwater. Over the seasons the highest exposures on the surface of the sea water were generally measured at 
either the west or north directions at the $45^{\circ}$ or horizontal alignments. Again, due to the fact they were not exposed to the same amount of sky view as the $45^{\circ}$ or horizontal dosimeters, the vertically aligned dosimeters measured UVB levels usually no more than half that measured by their $45^{\circ}$ and horizontal counterparts oriented towards the same direction. As an example, in the spring measurement campaign, along the eastern orientation at the surface, the vertically aligned dosimeter measured an average daily UVB exposure of $28 \mathrm{~kJ} \mathrm{~m}^{-2}$ day $^{-1}$, while comparatively the dosimeter at the horizontal alignment measured $73 \mathrm{~kJ} \mathrm{~m}^{-2}$ day ${ }^{-1}$ and the dosimeter at the $45^{\circ}$ alignment measured $65 \mathrm{~kJ} \mathrm{~m}^{-2}$ day $^{-1}$.

Unlike the underwater measurements made in both the creek and the agricultural dam, significant UVB measurements were able to be made at each depth from $5 \mathrm{~cm}$ down to $35 \mathrm{~cm}$ across the entirety of the measurement campaign. As was seen in the creek series of measurements, data obtained at the first depth underwater was significantly less in magnitude in comparison to measurements made at the water surface. For instance, in winter the value for UVB exposure obtained along the east direction at the horizontal inclination was measured to be $24 \mathrm{~kJ} \mathrm{~m}^{-2}$ day ${ }^{-1}$ in comparison to $15 \mathrm{~kJ} \mathrm{~m}^{-2}$ day $^{-1}$ which was measured at the same position $5 \mathrm{~cm}$ underwater. This represented a decrease of roughly 38\% in total UVB exposure.

From $5 \mathrm{~cm}$ deep to $20 \mathrm{~cm}$ deep and then again from $20 \mathrm{~cm}$ deep to $35 \mathrm{~cm}$ deep further considerable attenuation of the incoming UVB exposure was found to occur for every measurement series in the sea water. A good example of this can be seen in the spring measurement set, from the $5 \mathrm{~cm}$ depth to the $20 \mathrm{~cm}$ depth where a drop in UVB exposure of approximately $46 \%$ occurs at the horizontally aligned position facing 
south. Once more, at this same position, from the $20 \mathrm{~cm}$ depth to the $35 \mathrm{~cm}$ depth, a reduction of around $41 \%$ in the UVB exposure was measured to exist between the two. Another example of high UVB attenuation is seen at the $45^{\circ}$ alignment along the east direction in the autumn data set, where a reduction in UVB exposure of $37 \%$ was recorded between the $5 \mathrm{~cm}$ and $20 \mathrm{~cm}$ depths with a further $50 \%$ reduction in UVB exposure occurring between the $20 \mathrm{~cm}$ and $35 \mathrm{~cm}$ depths.

Unlike the creek water and the agricultural dam, it was found that the decrease in UVB exposure with increasing depth could be modelled with a good level of accuracy by using power law functions fitted to all of the exposure depth profiles for the sea water at each azimuth in every season. These equations each have the form:

$$
U V B_{\text {EXPOSURE }}=\psi Z^{-\omega}
$$

where $U V B_{\text {EXPOSURE }}$ is the UVB dosage measured by the dosimeter during the exposure time in units of $\mathrm{kJ} \mathrm{m}^{-2}$ and $z$ is the depth in units of $\mathrm{cm}$. Averaged UVB exposure depth profiles at $5 \mathrm{~cm}, 20 \mathrm{~cm}$ and $35 \mathrm{~cm}$ produced from the horizontally aligned sea water exposure distribution data can be viewed in Figure 4 for each season. The $y$-axis errors bars represent a calculated $\pm 18 \%$ range of uncertainty inherent within each data point. From Figure 4 it can be seen that the UVB data obtained in the sea water in summer are smaller overall in magnitude in comparison to the measurements made in autumn and spring and only slightly greater than the UVB measurements made in winter. This was due to a substantial amount of cloud coverage and rain being prevalent for roughly three days out of the six day summer measurement campaign greatly reducing incident amounts of solar UVB. 


\section{Agricultural dam}

Daily averaged UVB exposure measurement data recorded with the DSF in the agricultural dam in autumn, winter, spring and summer can be seen in Figure 3 (A), (B), (C) and (D) respectively. As was the case with the creek water and the sea water, the levels of UVB exposure recorded just above the water surface were the highest. Due to the very high level of UVB absorption present in the agricultural dam, no reliable data could be measured by the dosimeters underwater, except for some relatively small values found in each campaign. However, it is unclear if these measurements are reliable, as there were high amounts of soil discharge in the water that mildly stained the PPO dosimeter film. It is possible that this staining could have led to incorrect absorption values being measured by the spectrophotometer. Therefore, similarly to the creek water, no depth profiles could be provided for the agricultural dam water.

\section{Comparison of the Attenuation Coefficients Calculated in the Sea Water with the EPP2000 Spectrometer and the Dosimeters}

Figure 5 compares the $K_{d}$ values calculated from the sea water UVB exposure depth regimes compared to the averaged sea water $K_{d}$ value calculated using the EPP2000 spectrometer. The percentage variation calculated directly as $\frac{\sigma}{\mu} \cdot 100 \%$ for each $\mathrm{K}_{\mathrm{d}}$ estimation applicable to both the dosimeters and the EPP2000 spectrometer is represented in the figure by the $\mathrm{y}$-axis error bars. Using the dosimeters, the $\mathrm{K}_{\mathrm{d}}$ value in the sea water was estimated to be $0.045 \mathrm{~cm}^{-1}$ in summer, $0.073 \mathrm{~cm}^{-1}$ in winter, $0.043 \mathrm{~cm}^{-1}$ in autumn and $0.039 \mathrm{~cm}^{-1}$ in spring. The average value of these four measurements was found to be 0.049 with a standard deviation of \pm 0.017 . The averaged $K_{d}$ values determined with the EPP2000 spectrometer from the solar 
spectral UVB data sets obtained in early autumn and mid winter were found to be $0.028 \mathrm{~cm}^{-1}$ with a standard deviation of \pm 0.025 and 0.036 with a standard deviation of \pm 0.014 respectively.

Almost all of the $K_{d}$ values were found to be in relatively close agreement with each other in accordance to the estimated error margins. However, the winter $\mathrm{K}_{\mathrm{d}}$ estimation calculated with the dosimeters was found to be substantially greater in value in comparison with all the other $\mathrm{K}_{\mathrm{d}}$ approximations. This could have occurred due to the shading of the lower sections of the DSF in the sea water tank during high SZA conditions that are prevalent during winter especially in the early to mid morning and early to late afternoon. The dosimeters positioned primarily at the depths of $20 \mathrm{~cm}$ and $35 \mathrm{~cm}$ in the tank would have received a lower amount of UVB exposure during these intervals each day in comparison to their counterparts in the autumn, spring and summer measurement campaigns. By inspection of the modified Beer-Lambert-Law used to calculate the $K_{d}$ values for the dosimeters, it can be clearly seen that any reduction in measured UVB leads to an inevitable increase in the $K_{d}$ estimate. The agreement between the $K_{d}$ measurements measured by the dosimeters over the autumn, spring and summer seasons and the $K_{d}$ measurements made with the EPP2000 spectrometer in early autumn and mid winter was to be expected as it is known that the $\mathrm{K}_{\mathrm{d}}$ for any given water type is not influenced by changes in the incident solar spectrum brought on by annual changes in the Sun’s position [27].

\section{DISCUSSION}

The results produced in this research show that the PPO dosimeter provides comparable UVB exposure data compared to the spectrometric alternative within a 
good level of accuracy in types of water with little amounts of DOM and particulate matter, such as the sea water. The PPO dosimeter is useful in water with increased turbidity and DOM content for depths up to approximately $5 \mathrm{~cm}$. However, the usefulness of the PPO dosimeter at any depths greater than approximately $5 \mathrm{~cm}$ may be reduced in water with increased levels of water turbidity and DOM content, which both in turn reduce the overall UVB transmission and enhance the UVB absorption capabilities of the water leading to a reduction in the penetrative ability of the UVB. This was the case with the creek water and the agricultural dam water. In addition, in order to achieve accurate results with the PPO dosimeter, a rigid calibration regime such as the one carried out for this research must be applied in order to allow for variations in the solar UVB spectrum brought on by changes in the sun's position from season to season and to take into account any influence of column ozone fluctuations which may occur throughout the year.

It was seen from the measurements made with dosimeters in the creek water and in the agricultural engineering dam water that only small amounts of UVB exposure could be reliably recorded at the shallow depth of $5 \mathrm{~cm}$ in close to ideal conditions, with no UV recorded beneath that depth, even in high solar UVB conditions through summer, early autumn and late spring. This suggests that there is a characteristic limit to the depth at which the PPO dosimeter can be used underwater in water types with relatively high amounts of turbidity DOM content. In this research it appears that this limit is reached just below the $5 \mathrm{~cm}$ depth in water types having less than or equal to $75 \%$ UV transmission at a wavelength of $315 \mathrm{~nm}$, which was the value obtained for the creek water. However it can be used up to at least $35 \mathrm{~cm}$ in sea water. 
Not only do these water types like that found in the creek and the agricultural dam inhibit and attenuate the penetration of the solar UVB, but these water types are more likely to have free floating particulates and suspended masses of organic matter that could possibly condense on the dosimeter film and block out the UVB which would lead to distorted outcomes. Also, in creek, dam and estuary water type environments there is the possibility of the dosimeters being shaded by falling branches, leaves and other types of assorted plant matter which would further add to measurement uncertainty. One way to overcome these types of issues that occur at natural water locales such as dams, creeks and estuaries would be to check on and clean the dosimeters at regular intervals. However, this would be time consuming for the researcher and defeats the main purpose of the dosimeter, which is being able to leave it unattended underwater for extensive periods.

At this point in time it is recommended that this dosimeter only be used in 'cleaner' underwater locations distanced from influencing natural environmental factors like wildlife, shoreline trees and plants that have the potential to deposit various types of organic matter into the water. One such example of a 'cleaner' water locale would be in the ocean itself, preferably near or on a reef where frequent subsurface mixing takes place which would keep the water fresh and clear of any major contaminants. Fjords, such as those found in the Arctic regions and similar water bodies in Antarctica may also be an ideal location for PPO dosimeter measurements as the water found in them is sourced from glaciers or ice bergs, which is generally clear with an extremely high UV transmission capability. The PPO dosimeter could also be deployed in free flowing creeks, as the water in these locations is kept relatively clean due to its constant movement. 


\section{ACKNOWLEDGEMENTS}

The authors would like to thank both Graham Holmes and Oliver Kinder from the Faculty of Sciences, University of Southern Queensland for their technical assistance throughout this project. 


\section{REFERENCES}

[1] A.T. Banaszak, P.J. Neale. Limnol. Oceanogr. 46 (2001) 592- 603.

[2] B.E. Brown, R.P. Dunn, M.S. Goodson, A.E. Douglas, Nature 404 (2000) 142143.

[3] D.F. Gleason, G.M. Wellington, Nature 365 (1993) 836-838.

[4] S. Johnsen, E.A. Widder, Mar. Biol. 138 (2001) 717-730.

[5] M.P. Lesser, M.D. Lamare, M.F. Barker, Limnol. Oceanogr. 49(6) (2004) 19571963.

[6] M. Tedetti, R. Sempéré, Photochem. Photobiol. 82(2) (2005) 389-397.

[7] D-P. Hader, H.D. Kumar, R.C. Smith, R.C. Worrest, Photochem. Photobiol. Sci. 2 (2003) 39-50.

[8] D-P. Hader, H.D. Kumar, R.C. Smith, R.C. Worrest, J. Photoch. Photobio. B. 46 (1998) 53-68.

[9] H.W. Ducklow, C.A. Carlson, N.R. Bates, A.H. Knap, A.F. Michaels, Phil. Trans. R. Soc. B. 348 (1995) 161-167.

[10] D. Hanelt, H. Tug, K. Bischof, C. Gross, H. Lippert, T. Sawall, C. Wiencke, Mar. Biol. 138 (2001) 649-658.

[11] M.J. Dring, A. Wagner, L.A. Franklin, R. Kuhlenkamp, K. Luning, Helgoland Mar. Res., 55 (2001) 3-11.

[12] J. Frenette, M.T. Arts, J. Morin, Aquat. Ecol. 37 (2003) 77-85.

[13] A. Reinart, H. Arst, D.C. Pierson, Hydrobiologia, 547 (2005) 41-49.

[14] H. Schubert, S. Sagert, R.M Forster, Helgoland Mar. Res., 55 (2001) 12-22.

[15] R.P. Dunne, Mar. Ecol. Prog. Ser. 189 (1999) 53-63.

[16] P.C. Frost, A. Mack, J.H. Larson, S.D. Bridgham, G.A. Lamberti, Photochem. Photobiol. 82(3) (2006) 781-786. 
[17] R.A. Lester, A.V. Parisi, M.G. Kimlin, J. Sabburg, Phys. Med. Biol. 48 (2003) 3685-3698.

[18] A. Davis, G.W.H Deane, D. Gordon, G.V. Howell, K.J. Ledbury, J. Appl. Polym. Sci. 20 (1976) 1165-1174.

[19] A. Davis, B.L. Diffey, B.K. Tate, Photochem. Photobiol. 34 (1981) 283-286.

[20] B. Berre, D. Lala, Sol. Energy. 42(5) (1989) 405-416.

[21] P. Schouten, A. Parisi, D.J. Turnbull, Photochem. Photobiol. 83(4) (2007) 931937.

[22] P.W Schouten, A.V. Parisi, D.J. Turnbull, J. Photoch. Photobio. B. 91(2-3) (2008) 108-116.

[23] G.R Casale, M. Borra, A. Colosimo, M. Colucci, A. Militello, A.M. Siani, R. Sisto, Phys. Med. Biol. 51 (2006) 4413-4427.

[24] G. Zibordi, J. Atmos. Ocean. Tech. 23 (2005) 302-313.

[25] S.B. Hooker, G. Zibordi, J. Atmos. Ocean. Tech. 22 (2005) 757-770.

[26] G. Zibordi, S.B. Hooker, J. Mueller, G. Lazin, J. Atmos. Ocean. Tech. 21 (2004) $501-514$

[27] J.T.O Kirk, Light and photosynthesis in aquatic ecosystems, Cambridge University Press, Cambridge, 1994. 


\section{FIGURE AND TABLE LEGENDS}

Figure 1 - (A) North side view of the DSF and (B) the top-down view of the DSF.

Figure 2 - Transmission (A) and absorption (B) spectrophotometry data at $315 \mathrm{~nm}$ for the clear, creek, dam and sea water.

Figure 3 - UVB exposure distributions in the creek, sea and dam water in autumn (A), winter (B), spring (C) and summer (D).

Figure 4 - Averaged UVB exposure depth regimes as extracted from horizontally aligned sea water exposure distribution data for each season of the year.

Figure $5-K_{d}$ values calculated from the sea water UVB exposure depth regimes compared to the $K_{d}$ value calculated using the EPP2000 spectrometer for sea water. 
A

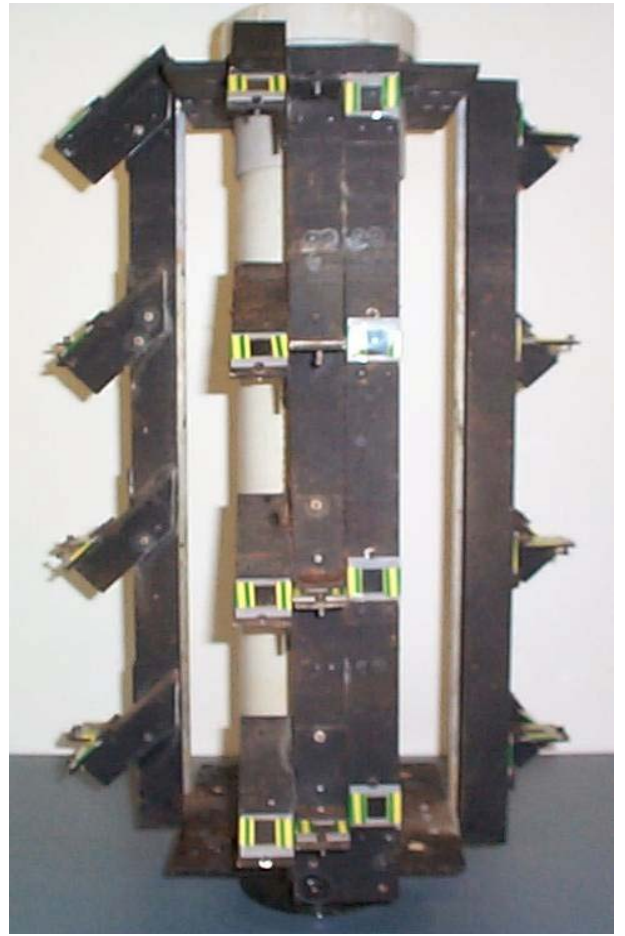

B

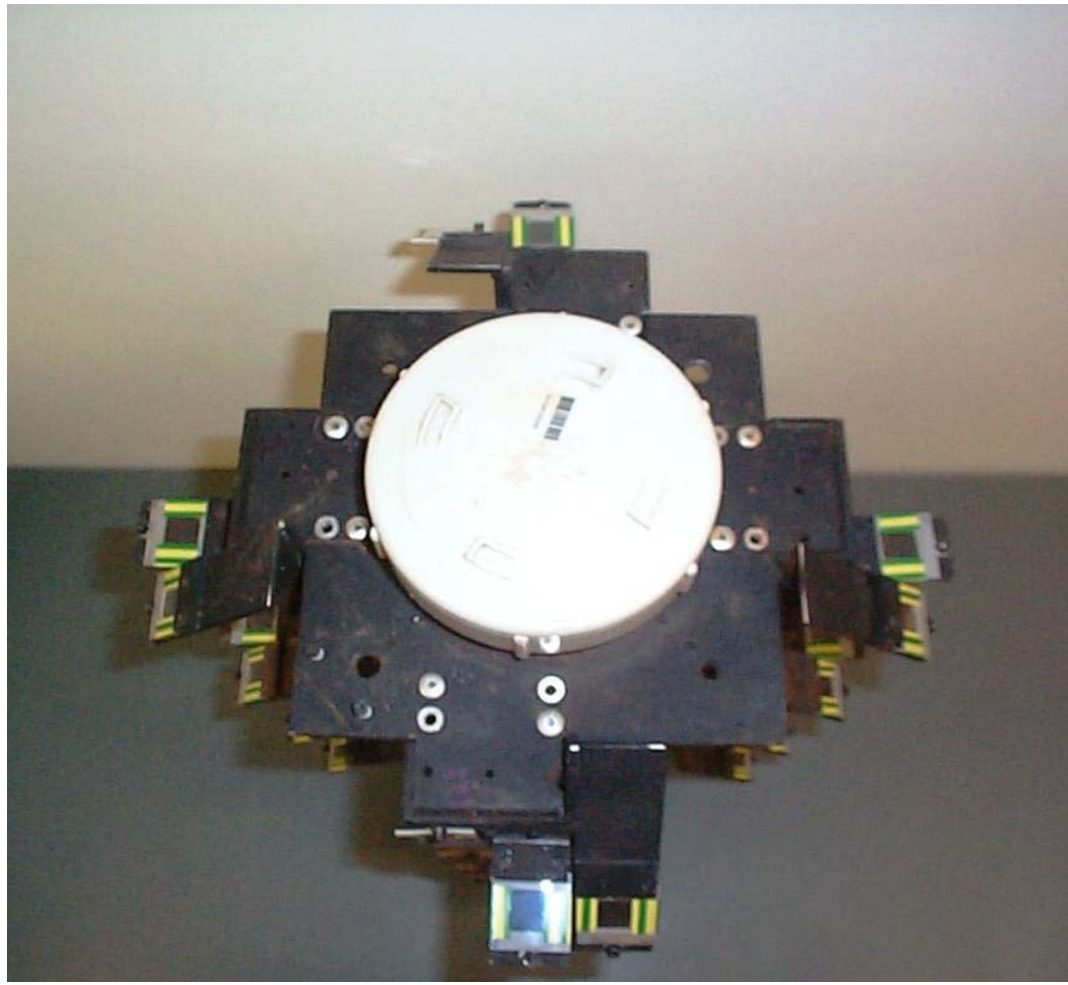

Figure 1 - (A) North side view of the DSF and (B) the top-down view of the DSF. 


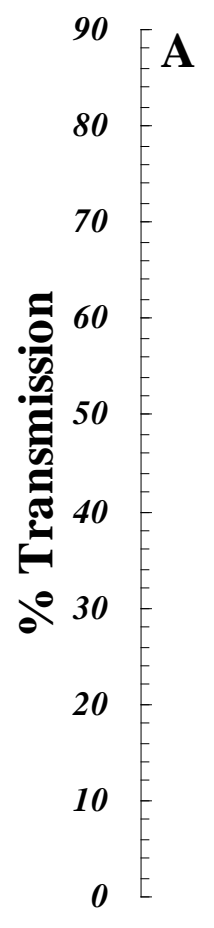

- Clear Water

$\square$ Creek Water

$\square$ Sea Water

$\square$ Dam Water
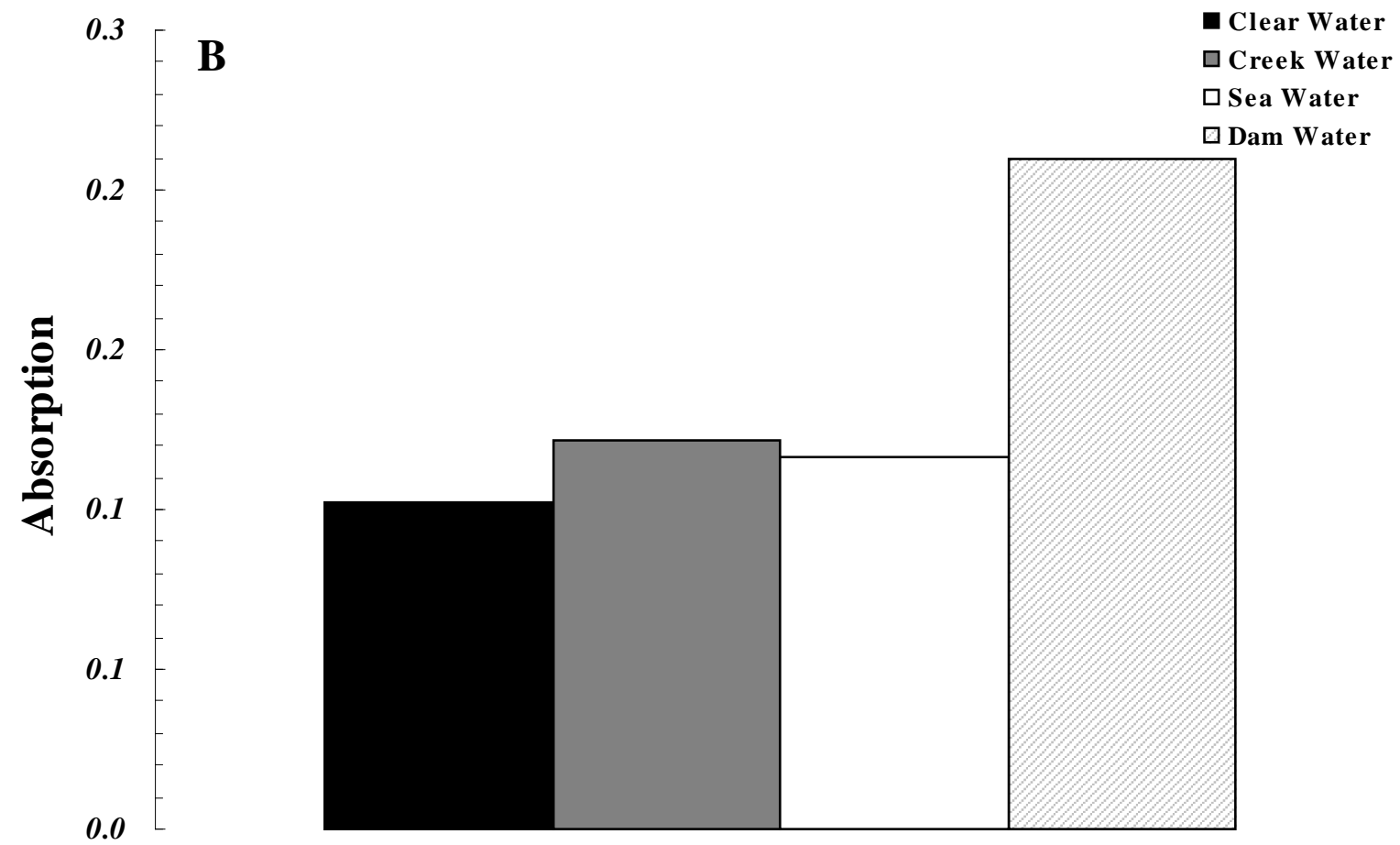

Figure 2 - Transmission (A) and absorption (B) spectrophotometry data at $315 \mathrm{~nm}$ for the clear, creek, dam and sea water. 

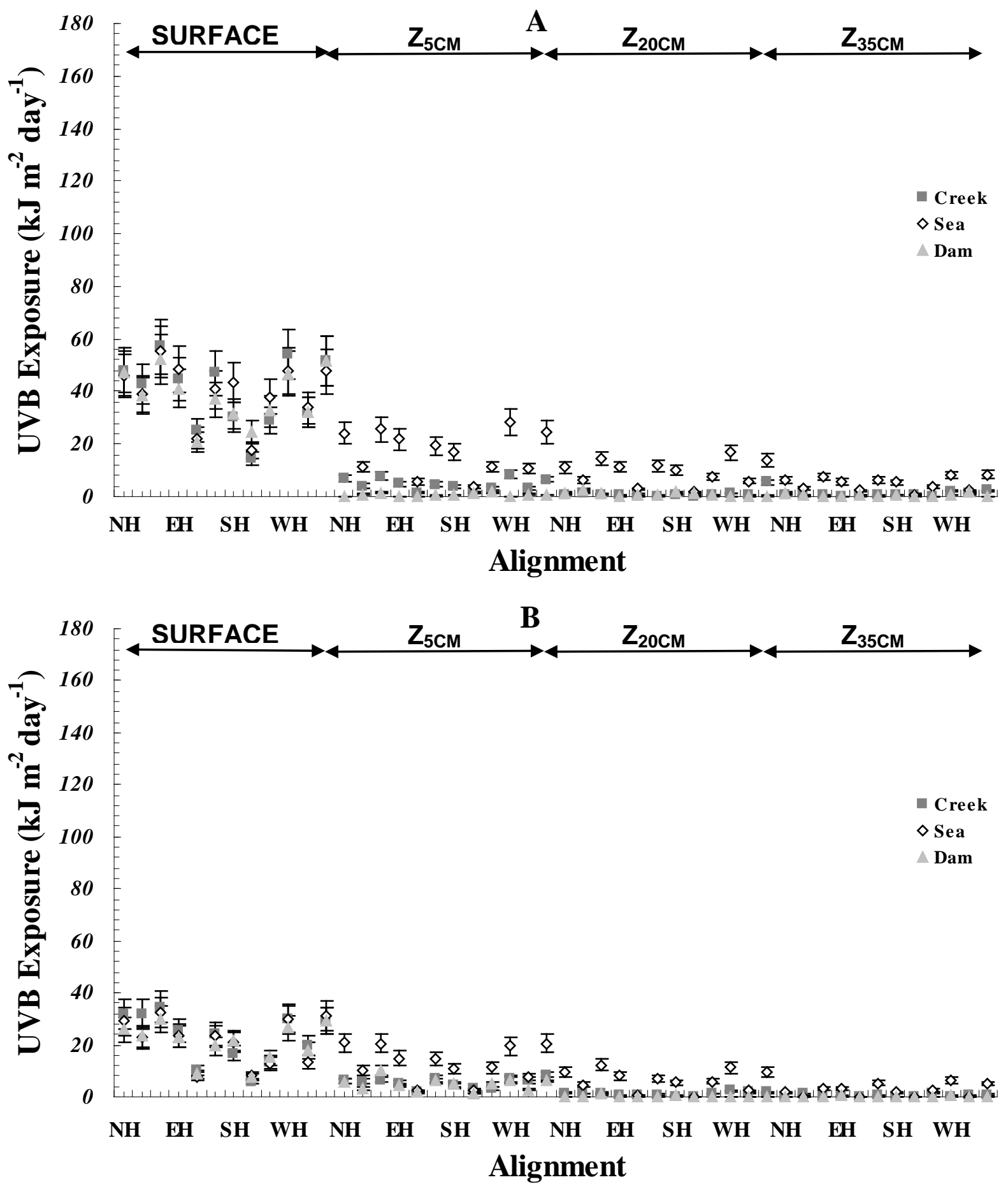

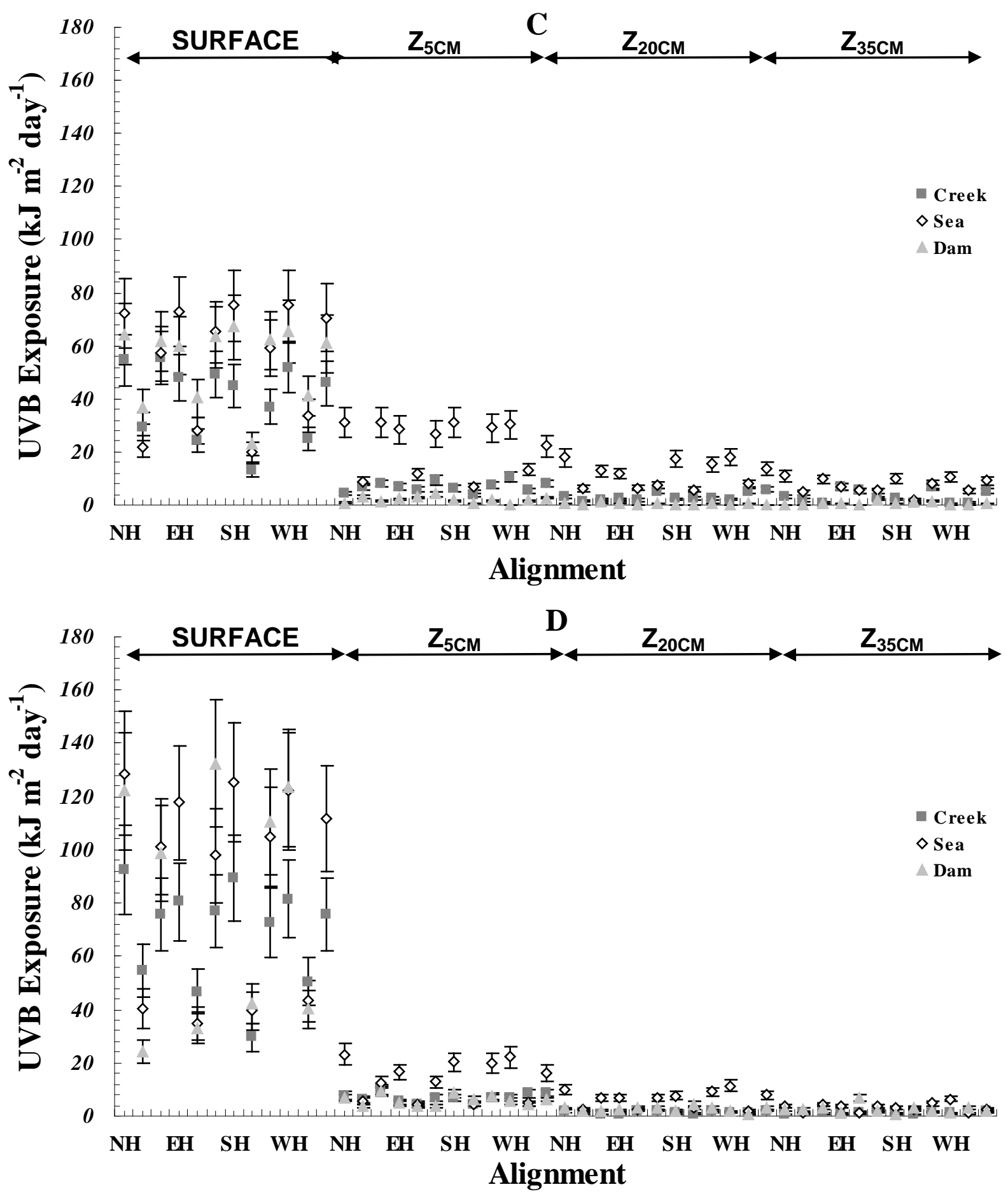

Figure 3 - UVB exposure distributions in the creek, sea and dam water in autumn (A), winter (B), spring (C) and summer (D). 


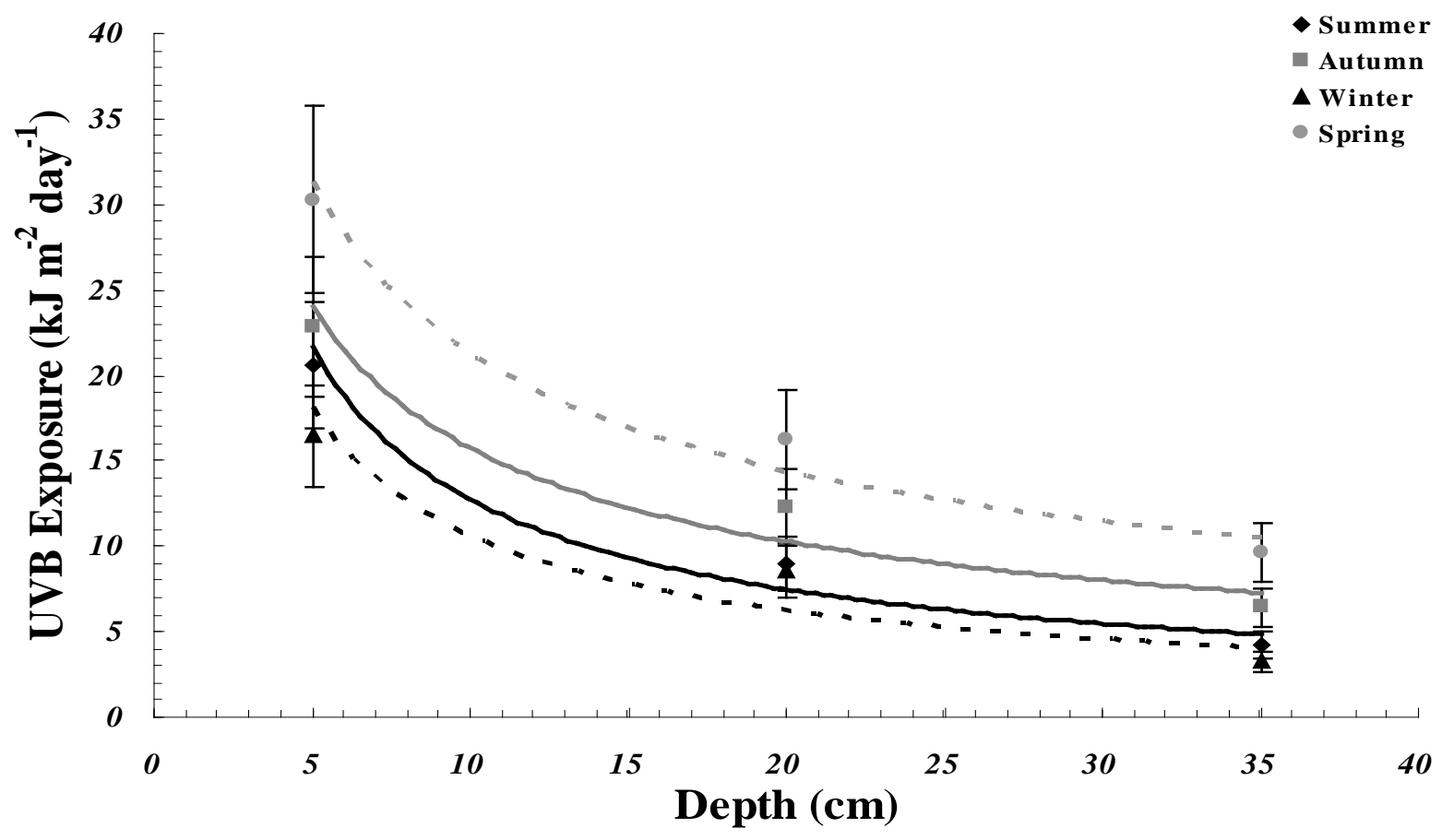

Figure 4 - Averaged UVB exposure depth regimes as extracted from horizontally aligned sea water exposure distribution data for each season of the year. 

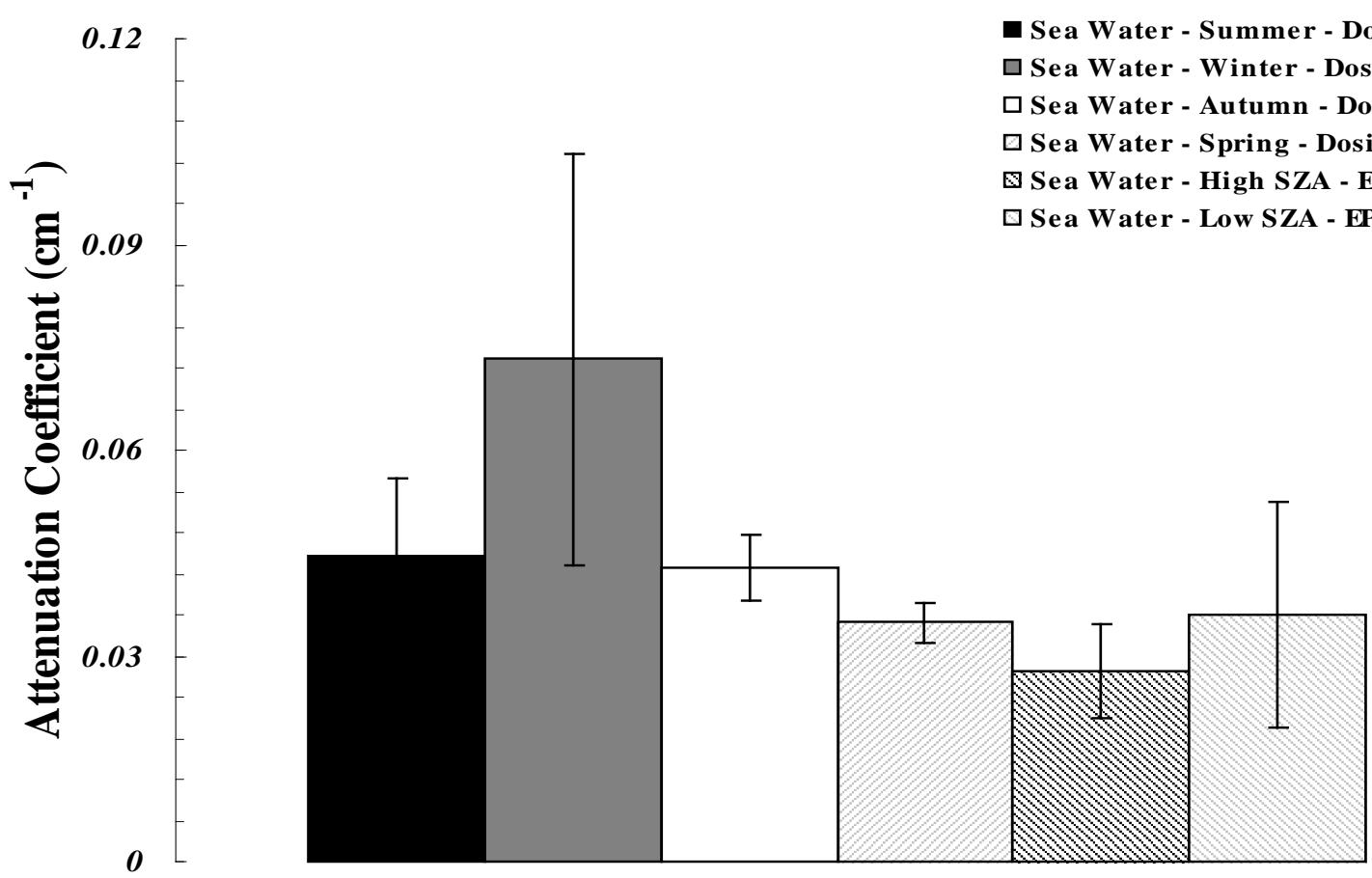

Figure $5-K_{d}$ values calculated from the sea water UVB exposure depth regimes compared to the $\mathrm{K}_{\mathrm{d}}$ value calculated using the EPP2000 spectrometer for sea water. 